\title{
Examining the effect of biofuel industry on Thailand's economy dependent on input-yield model
}

\author{
Thipruedee Limchaikit ${ }^{1 *}$, Thitisak Boonpramote ${ }^{2}$, and Pongsun Bunditsakulchai ${ }^{3}$ \\ ${ }^{1}$ Chulalongkorn University, Graduate School, Bangkok, Thailand \\ ${ }^{2}$ Chulalongkorn University, Faculty of Engineering, Bangkok, Thailand \\ ${ }^{3}$ Chulalongkorn University, Faculty of Engineering, Bangkok, Thailand
}

\begin{abstract}
This examination is to consider the effect of the biofuel business incorporates ethanol and biodiesel, to Thailand's Economy by utilizing Input-Output examiner. Thailand's Alternate Energy Development Plan (AEDP) has been advancing the biofuel business persistently in the previous ten years by sponsoring biofuel items and propelled command strategy. This arrangement is concentrating on expanding residential elective vitality use to supplant petroleum derivative imports and increment inside vitality security. In any case, the test of this industry is the items' value seriousness with customary fuel, and appropriation is required to cause this industry to continue in the market. Right now, we have constrained information about the monetary ramifications. The principle goal of this investigation is to concentrate on the effect of the biofuel business on every industry part and an total yield of Thailand's economy. Thus, the biofuel business can expand the complete yield of the Thai economy, family unit pay. Nonetheless, this industry has a somewhat negative on expense and worth included. From upsides and downsides correlation, despite the fact that the administration marginally misfortune advantage in duty and worth included, yet that advantage goes to family unit salary. Thus, biofuels advancement is suggested.
\end{abstract}

\section{Foundation and explanation of the issues}

Biofuels, including ethanol and biodiesel, are the two most generally utilized fuel types to supplant customary fuel in numerous nations, got from molasses and cassava for ethanol and squandered cooking oil, palm stearin, unrefined palm oil for biodiesel. It very well may be mixed with ordinary oil fuel to improve its octane level bringing about diminished ozone harming substance emanations. All the biofuel items in Thailand are expending locally in the vehicle segment.

Transport is one of the most basic frameworks in each nation. It assumes a fundamental job in financial development and globalization by finding individuals, products, and innovations starting with one spot then onto the next. There are various kinds of

\footnotetext{
* Corresponding author: thipruedee.1@gmail.com
} 
transportation; via air, via ocean, and via land. Seventy-six percent of vitality in Thailand is expended in the street or transport part, which is the most huge division as far as vitality utilization. [1]. In addition to the fact that petroleum uses as vitality for the transportation segment, however there is likewise fuel broadening by mixing biofuel or sustainable power sources in gas, as referenced.

The fundamental explanations behind mixing biofuel into fuel are to lessen oil importation, to the extent autonomy from imported oil, empowering horticultural development and advancing local markets for rural wares, making provincial business, and improving rancher pay just as carbon oxide outflow decrease. [2] There are a few advantages to utilizing biofuel as regular fuel replacement, as referenced. Be that as it may, biofuel items, for example, ethanol and biodiesel cost are altogether higher than unleaded fuel costs at the current circumstance for both benzene and diesel (2019). The administration bolsters the biofuel business by sponsoring the retail cost of the mixed gas through oil support, bringing about fuel with biofuel mixed has lowed retail cost for purchaser fascination except if the biofuel business couldn't get by because of less value seriousness.

\subsection{Ethanol current situation and AEDP plan}

Thailand was the principal nation in Asia to declare national approaches for bioethanol, constantly advance ethanol utilization in the nation, and give individuals more trust in biofuels. The administration underpins the ethanol business by organized oil evaluating to make retail costs of gasohol lower than ULG retail cost, and the State Oil Fund gave the value sponsorships. Since 2013, unleaded gas 91 octane has been restricted and supplanted with E10 or gasohol 91, which raised ethanol utilization fundamentally, from 1.3 million liters/day in 2012 to 2 million liters/day in 2013 [3]. AEDP $(2015$ - 2036) directed ethanol utilization 11.3 million liters/day. Be that as it may, the ethanol utilization in 2018 was 4 million/litter every day, and anticipating the utilization will be just 5.7 million liters/day in 2036 [4], which has in excess of 5 million litter/day hole contrasted with AEDP target.

There are three vital strides for the starch-based ethanol creation process. The initial step is to separate starch regularly from cassava into disintegrated sugars; this progression incorporates processing, cooking, and liquefaction. Catalysts will change over this starch into straightforward sugar - furthermore, maturation process. After the starch is hydrolyzed into sugar, the sugar will be taken care of into a maturation vessel to create ethanol. During maturation, yeast changes over the glucose (sugar) into ethanol. The last advance is purging or refining. Where substances are isolated by their breaking point during refining and further amassed into high virtue ethanol for mixing into fuel. For sugar-based ethanol, the procedure prohibits the hydrolysis step.

In Thailand, ethanol maker normally separated into three gatherings identified with the feedstock; First, cassava ethanol plant, molasses, and stick juice ethanol plant, and cassava/molasses ethanol plant for the plants that ready to utilize the two feed stocks.

\subsection{Biodiesel current situation and AEDP plan}

Biodiesel mixing rates began with B2 or 2 percent biodiesel since 2008 and somewhat expanded the mixing proportion until B5 required in 2016, trailed by a compulsory mixing pace of B5. The administration has an arrangement to execute the necessary norm to B10 in 2018 for all diesel deals. Feedstock gets one of the most basic variables to biodiesel achievement infiltration in the Thai market, the way that oil palm needs more expanded time for ranch until collect, at any rate 3-4 years. From AEDP biodiesel utilization focuses at 5.1 billion litters by 2036 or 14 million litter for every day. The current circumstance is in a similar circumstance as ethanol, the utilization in 2015 demonstrated just 3.40 million litter 
for each day (Thailand interchange Energy, 2015), which despite everything has an impressive hole utilization left contrasted with AEDP.

Biodiesel (B100) can be created from vegetable oil, creature fats and utilized cooking oil. The creation procedure changes over littler particles to an ethyl ester and methyl ester, items that can be utilized instead of standard diesel. The fuel is created by transesterification - a procedure that changes over fats and oils into biodiesel and glycerin (a coproduct). In Thailand there are numerous feedstock types can have the option to use as a feedstock to create biodiesel incorporates vegetable oil, rough palm oil (CPO), palm stearine, aerated palm oil (RBDPO) and freshened up palm stearine (RBDPS) [5]

\section{Research methodology}

The examination means to evaluate absolute yield and other financial effects of the biofuel creation frameworks in Thailand by thought of the biofuel business as a regular fuel auxiliary. The key components of financial improvement are examined, including monetary impacts, business impact, charge impact, and total national output (GDP). The information asset is from the 2010 Input-Output distributed by the National Economic and Social Development Board (NESDB) in $180 \times 180$ divisions. The count strategies show in area 2.1 and 2.2.

\subsection{Input-yield table and Leontief converse}

The input-Output table is fundamental information describing the side behavior of an economic system, concerns the flows of products from each industrial sector, considered as a producer, to each of the sectors, itself, and others felt as consumers. This necessary information from which an input-output model is developed contained in an interindustry transactions table or intermediate transaction. Each row describes the distribution of a producer's output throughout the economy. The column represents the composition of inputs required by a particular industry to produce its output showed in Table 1.

Where $Z i j$ speaks to exchanges between sets of parts from every area I to every segment j. $I=1,2, \ldots, n$ shows middle of the road contribution as makers businesses $j=1,2, \ldots, n$. Which consider as moderate requests between ventures. Expect that the economy can be arranged into $\mathrm{n}$ divisions.

fi refers to conclusive interest for every division, record the deals by every part to definite markets for their creation $v$ i refers to esteem included of makers, represent the other (nonmodern) contributions to creation, for example, work, devaluation of capital, circuitous business charges, and imports.

$x \mathrm{i}$ is the whole yield of creation part I, and by fi the absolute last interest for area I's item, the bookkeeping balance is portrayed as follows. Which area I appropriates its item through deals to different areas and last interest.

$$
x_{i}=z_{i 1}+\cdots+z_{i j}+\cdots+z_{i n}+f_{i}=\sum_{j=1}^{n} z_{i j}+f_{i}
$$

Decide lower-case strong letters for (section) vectors and capitalized letters for framework. We can survey Equation (1) in direct polynomial math shows in Equation (2).

$$
\boldsymbol{x}=\boldsymbol{Z} \boldsymbol{i}+\boldsymbol{f}
$$

Where I to speak to a section vector of 1's of proper $n$ measurement The all out yield incorporates family unit utilization, private venture, government utilization, and fares.

The presumption of the Input-Output model is as per the following 
- The crude materials utilized in a similar creation divisions are thought to be the equivalent and thought to be not comparable in various creation parts

- In a brief period (not more than 3-5 years), crude material utilized in every creation division is considered as a consistent extent, with no thought of economy of scale, non-substitutability. Subsequently, the value should be fixed

The equation that will be used for this study is Leontief inverse equation shows in Equation (3)

$$
\boldsymbol{x}=(\boldsymbol{I}-\boldsymbol{A})^{-1} \boldsymbol{f}=\boldsymbol{L f}
$$

From the Leontief reverse condition in Equation (3), this will be utilized as the beginning stage for this examination to contemplate the effects on biofuel Industry Outputs on the Thai economy.

\subsection{Multiplier}

Table 1. Input-Output Table.

\begin{tabular}{cccccccc}
\hline \hline \multirow{2}{*}{ Producers } & \multicolumn{7}{c}{ Producer as Consumers } \\
\cline { 2 - 6 } & 1 & $\cdots$ & $j$ & $\ldots$ & $n$ & Final Demand & Total Output \\
\hline 1 & $z_{11}$ & $\ldots$ & $z_{1 j}$ & $\ldots$ & $z_{1 n}$ & $f_{1}$ & $x_{1}$ \\
2 & $z_{21}$ & $\ldots$ & $z_{2 j}$ & $\ldots$ & $z_{2 n}$ & $f_{2}$ & $x_{2}$ \\
$\vdots$ & $\vdots$ & $\ddots$ & $\vdots$ & $\ddots$ & $\vdots$ & $\vdots$ & $\vdots$ \\
$n$ & $z_{n 1}$ & $\ldots$ & $z_{n j}$ & $\ldots$ & $z_{n n}$ & $f_{n}$ & $x_{n}$ \\
\hline Value Added & $v_{1}$ & $\ldots$ & $v_{j}$ & $\ldots$ & $v_{n}$ & & \\
\hline \hline
\end{tabular}

The multiplier is a coefficient that depicts the impact on the economy from the difference in outer elements (Exogenous alteration), particularly in a distinction in the 1 unit of definite interest. The overall structure of multiplier examination is the estimation of the impacts of exogenous changes on yields of the areas in the economy, pay earned by family units in every segment in view of the new yields, work produced in every division due to the new yields and worth included that is made by every part in the economy due to the new yields [6] A yield multiplier for the division is characterized as the complete estimation of creation in all areas of the economy that is important to fulfill 1 unit cash worth of conclusive interest for the segment's yield. The basic yield multiplier for the area can be written in Equation (4)

$$
m(o)_{j}=\sum_{i=1}^{n} l_{i j}
$$

Rework to direct variable based math condition shows in Equation (5)

$$
\boldsymbol{m}(o)=\boldsymbol{i}^{\prime} \boldsymbol{L}
$$

Where, $I^{\prime}$ is a vector of the lattice I or $[1, . ., 1]$

By and large, investigators are more intrigued by the effect of changing last interest as far as work or family unit pay more than the complete yield of every division. Pay Multiplier is normally used to examine the effect of conclusive interest, which is determined by duplicating Leontief Inverse by the vector of the coefficient of vector (work coefficient,) as appeared in the Equation (6) 


$$
\boldsymbol{\varepsilon}^{\prime}=\mathbf{e}^{\prime} \hat{\mathbf{x}}^{-1}
$$

Where is the vector of employment

Revenue multiplier as appeared in the Equation (7)

$$
m(h)_{j}=\sum_{i=1}^{n} \varepsilon_{i} l_{i j}
$$

Rework the condition to direct algebra math condition, as appeared in Equation (8)

$$
\boldsymbol{m}(h)=\boldsymbol{\varepsilon}^{\prime} \boldsymbol{L}
$$

\section{Result and discussion}

The information source for this examination is from the 2010 Input-Output distributed by the National Economic and Social Development Board (NESDB) in 180 x 180 segments. To adjust to the financial structure and biofuel-advancing estimates contained in Thailand's AEDP plan, we made three new industry parts;

1. Molasses-Ethanol, split from sugar and refining mixing spirits

2. Cassava-Ethanol, split from tapioca processing

3. Biodiesel, split from oil palm and coconut and palm oil

We likewise disaggregated eight areas from processing plant items to Gasoline, Gasohol 95 E10, Gasohol 91 E10, Gasohol E20, Gasohol E85, B5 Diesel, B10 Diesel, and other treatment facility items.

After we made three new biofuels areas and disaggregated eight parts from the treatment facility items segment, another Input-Output table will comprise of 191x191 divisions. The assets of the information are from; information from biofuel makers, the monetary report of biofuel makers, Brazil's Input-Output table from IBGE, and Japan's Input-Output table from MIC. From 191 parts, we joined into 44 divisions to concentrate on the areas that are probably going to be affected by the biofuel business, shows in Table2.

Table 2. Input-Output 44 sectors.

\begin{tabular}{|c|l|c|l|}
\hline Sector & \multicolumn{1}{|c|}{ Industry } & Sector & \multicolumn{1}{|c|}{ Industry } \\
\hline S01 & Cassava & S23 & B5 Diesel \\
\hline S02 & Sugarcane & S24 & B10 Diesel \\
\hline S03 & Coconut & S25 & Refinery products \\
\hline S04 & Other Crops & S26 & Other petroleum products \\
\hline S05 & Livestock & S27 & Rubber products and plastic wares \\
\hline S06 & Forestry and fishery & S28 & $\begin{array}{l}\text { Cement and concrete products and } \\
\text { nonmetallic product }\end{array}$ \\
\hline S07 & Crude oil and coal & S29 & $\begin{array}{l}\text { Iron, steel, non-ferrous metal and } \\
\text { fabricated metal products }\end{array}$ \\
\hline S08 & Metal ore and non-metal ore & S30 & Industrial machinery \\
\hline S09 & Manufacturing of foods & S31 & Electrical machinery and apparatus \\
\hline S10 & $\begin{array}{l}\text { Coconut and palm oil and } \\
\text { vegetable animal oils }\end{array}$ & S32 & $\begin{array}{l}\text { Motor vehicles and repairing and } \\
\text { transportation equipment }\end{array}$ \\
\hline S11 & Sugar refineries & S33 & Manufacturing products \\
\hline S12 & $\begin{array}{l}\text { Spinning, weaving and bleaching } \\
\text { and textile item }\end{array}$ & S34 & Electricity \\
\hline S13 & $\begin{array}{l}\text { Leather products, sawmills, and } \\
\text { wood products }\end{array}$ & S35 & Gas \\
\hline S14 & $\begin{array}{l}\text { Paper and paper products, printing } \\
\text { and distributing }\end{array}$ & S36 & Waterworks and supply \\
\hline S15 & Chemical products & S37 & Construction \\
\hline
\end{tabular}




\begin{tabular}{|l|l|l|l|}
\hline S16 & Ethanol & S38 & Trade \\
\hline S17 & Biodiesel & S39 & Transportation and communication \\
\hline S18 & Gasoline & S40 & Restaurants and hotels \\
\hline S19 & Gasohol 95 & S41 & Public services \\
\hline S20 & Gasohol 91 & S42 & Business services \\
\hline S21 & Gasohol E20 & S43 & Personal services \\
\hline S22 & Gasohol E85 & S44 & Unclassified \\
\hline
\end{tabular}

A starter concentrate by utilizing Leontief Inverse by utilizing Equation 3, to examine the coefficients or monetary multipliers that measure the impact on the economy. An expansion underway by a downstream maker gives positive financial externalities to an upstream producer. The middle utilization is, thusly, created by different branches using new moderate utilization, etc. [7]. The outcome appeared in Figure 1.

Therefore, the main 3 businesses that have the most elevated impact on the economy are Gasohol E85, Electrical Machinery and Apparatus, and Industrial Machinery. From the regressive linkage result, it tends to be inferred that Gasohol E85 has a long flexibly chain, which highly affects Thailand's Economy.

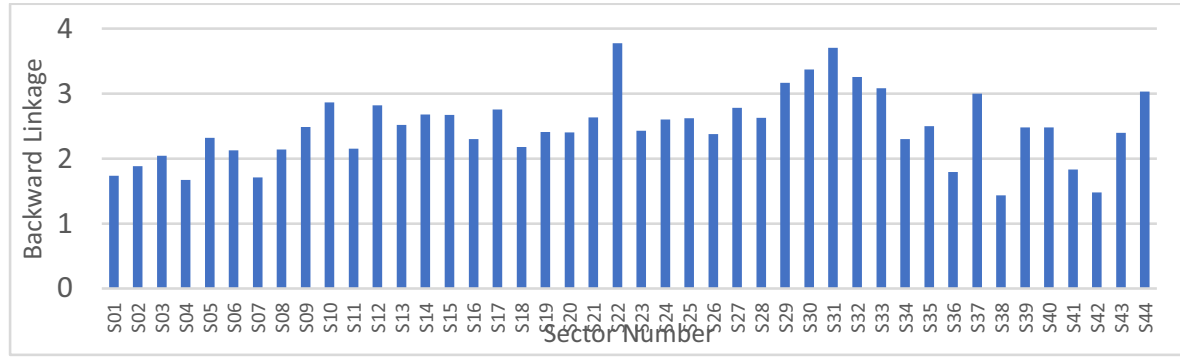

Fig. 1. Backward linkage of each industry.

Three situations are established to contrast the impact with Thailand's economy between the various proportions of biofuel utilized. Accepting the development of gas and diesel request in Thailand is at $3 \%$ or about 6.3 billion THB.

- Baseline. The expansion in the interest in gas and diesel falls into a similar proportion

- Scenario 1. The legislature is fruitful in elevating biofuel to have the option to diminish regular fuel, E10, and B5 diesel by $20 \%$. This $20 \%$ of new interest tumbles to E20, E85, and B10

- Scenario 2. The administration dispatches the new strategy with the augmentation of the biofuel mixed command. Fuel and E10 are supplanted by E20; furthermore, B5 is supplanted by B10. That new interest 70\% tumbles to E20, 30\% tumbles to E85.

- Scenario 3. The expansion in the interest falls into E20 and B10

\subsection{The impact on total output of Thailand's economy}

The significant utilization of the data in an information yield model are to survey the impact on an economy of changes in components that are exogenous to the model of that economy by utilizing Equation 4. The correlation of yield multipliers would show where this spending would have the most noteworthy effect as far as the entire dollar estimation of yield created all through the economy. Consequently, the absolute effect for every situation shows in Table 
3. The situation with a higher biofuel mixed item utilized gave the most noteworthy effect on the Thai economy.

Table 3. The result of total output comparison.

\begin{tabular}{|c|c|c|}
\hline & Delta Total Output $\left(\mathbf{x 1 0}^{\mathbf{3}} \mathbf{T H B}\right)$ & \% Comparison \\
\hline Baseline & $15,593,766$ & - \\
\hline Scenario I & $16,008,775$ & $+2.66 \%$ \\
\hline Scenario II & $16,987,544$ & $+8.94 \%$ \\
\hline Scenario III & $16,738,053$ & $+7.34 \%$ \\
\hline
\end{tabular}

\subsection{The impact on income}

To examine the absolute yield, we are bound to be worried about the monetary effects of expanded family profit or pay as opposed to just gross yield by part. The investigation of the pay indicated a similar pattern as complete yield. The situation with a higher biofuel mixed item utilized gave the most noteworthy effect on the Thai economy appeared in Table 4.

Table 4. The result of income comparison.

\begin{tabular}{|c|c|c|}
\hline & Delta Total Income $\left(\mathbf{x 1 0}^{\mathbf{3}} \mathbf{T H B}\right)$ & \% Comparison \\
\hline Baseline & $1,764,153$ & - \\
\hline Scenario I & $1,800,394$ & $+2.05 \%$ \\
\hline Scenario II & $1,914,544$ & $+8.52 \%$ \\
\hline Scenario III & $1,903,260$ & $+7.89 \%$ \\
\hline
\end{tabular}

\subsection{The impact on tax}

We additionally examined the effect on expense, and this can be the organization line for the administration to think about the arrangement execution. The most testing piece of the biofuel business for the legislature is on endowment spending. Nonetheless, the administration additionally procure billions of THB every year from gas and regular processing plant items. For the examination, as we suspected, the situation with more biofuel item mixes produces less duty for the legislature. The outcome appeared in Table 5.

Table 5. The result of tax comparison.

\begin{tabular}{|c|c|c|}
\hline & Delta Tax $\left(\mathbf{x 1 0}^{\mathbf{3}} \mathbf{T H B}\right)$ & \% Comparison \\
\hline Baseline & $1,710,233$ & - \\
\hline Scenario II & $1,548,716$ & $-9.44 \%$ \\
\hline Scenario II & $1,156,441$ & $-32.38 \%$ \\
\hline Scenario III & $1,249,385$ & $-26.95 \%$ \\
\hline
\end{tabular}

\subsection{The impact on Value-Added}

The worth included is a superior proportion of a part's commitment to an economy than complete yield, since it genuinely catches the worth that is included by the area in taking part underway - the distinction between a segment's all out yield and the expense of its moderate data sources. Worth included is one of the significant variables that sway the nation's GDP. Biofuel division created less worth included than the ordinary treatment facility items. Thus, the area with more biofuel mixed gave less worth included appeared in Table 6. This outcome 
implies the bio-refinery area has a high effect however less worth included coefficient than the processing plant items segment.

Table 6. The result of Value-Added comparison.

\begin{tabular}{|c|c|c|}
\hline & Delta Total Value-Added $\left(\mathbf{x 1 0}^{\mathbf{3}} \mathbf{~ T H B}\right)$ & \% Comparison \\
\hline Baseline & $6,466,701$ & - \\
\hline Scenario II & $6,458,901$ & $-0.12 \%$ \\
\hline Scenario II & $6,451,304$ & $-0.24 \%$ \\
\hline Scenario III & $6,459,948$ & $-0.10 \%$ \\
\hline
\end{tabular}

\subsection{Conclusion}

This study shows that implementing biofuel policy yields a benign effect on Thai economy. The increase in the mandate for not only gasoline but also diesel to E20 including B10 will be able to increase total output and household income. However, this scenario will decrease tax, which is government income. Furthermore, it will also decrease value-added, which will affect Thailand's GDP in a slightly negative way, a change in the ratio between E20 and E85 impacts on GDP. The policy needs to be carefully considered and weigh the pros and cons of this biofuel industry. However, the additional study required, e.g., feedstock availability, water irrigation, harvest area, and production capacity.

\section{References}

1. Thailand-Word Bank Country Development (2018).

2. T. Nguyen, S.H. Gheewala, S. Bonnet, Life cycle cost analysis of fuel ethanol produced from cassava in Thailand, (2007).

3. Thailand Alternative Fuel Update, (2017).

4. N. Tunpaiboon, ETHANOL, (2017).

5. N. Tunpaiboon, BIODIESEL, (2018).

6. R.E. Miller, P.D. Blair, Input-Output Analysis Foundations and Extension (2009).

7. Eustat, [Online], https://en.eustat.eus/documentos/elem_15552/definicion.html.

8. Thai Agro Energy Public Company Limited Report and financial statements, (2019).

9. Updated Input-Output Table, [Online], https://www.meti.go.jp/english/statistics/tyo/entyoio/index.html.

10. Thailand's Input-Output Table, [Online], https://www.nesdc.go.th/ewt_w3c/main.php?filename=io_page.

11. Input-Output Matrix, [Online]. https://www.ibge.gov.br/en/statistics/economic/national-accounts/16940-input-outputmatrix.html? $=\& \mathrm{t}=\mathrm{o}$-que-e.

12. T. Ngamsangiam, Economic Impact of The Shift in Transportation Model of Cement and its Related Industries, (2018).

13. S. Wianwiwat, J. Asafu-Adjaye, Is there a role for biofuels in promoting energy self sufficiency and security?, (2012).

14. DEDE, TheAlternativeEnergyDevelopmentPlan (AEDP2011-2021), (2012). 